University of Texas at El Paso

ScholarWorks@UTEP

$11-2020$

\title{
A Natural Formalization of Changing-One's-Mind Leads to Square Root of "Not" and to Complex-Valued Fuzzy Logic
}

Olga Kosheleva

University of Texas at El Paso, olgak@utep.edu

Vladik Kreinovich

University of Texas at El Paso, vladik@utep.edu

Follow this and additional works at: https://scholarworks.utep.edu/cs_techrep

Part of the Computer Sciences Commons, and the Mathematics Commons

Comments:

Technical Report: UTEP-CS-20-120b

Published in Julia Rayz, Victor Raskin, Scott Dick, and Vladik Kreinovich (eds.), Explainable Al

and Other Applications of Fuzzy Techniques, Proceedings of the Annual Conference of the North American Fuzzy Information Processing Society NAFIPS'2021, West Lafayette, Indiana, June 7-9, 2021, Springer, Cham, Switzerland, 2022, pp. 190-195

\section{Recommended Citation}

Kosheleva, Olga and Kreinovich, Vladik, "A Natural Formalization of Changing-One's-Mind Leads to Square Root of "Not" and to Complex-Valued Fuzzy Logic" (2020). Departmental Technical Reports (CS). 1517. https://scholarworks.utep.edu/cs_techrep/1517

This Article is brought to you for free and open access by the Computer Science at ScholarWorks@UTEP. It has been accepted for inclusion in Departmental Technical Reports (CS) by an authorized administrator of ScholarWorks@UTEP. For more information, please contact Iweber@utep.edu. 


\title{
A Natural Formalization of Changing-One's-Mind Leads to Square Root of "Not" and to Complex-Valued Fuzzy Logic
}

\author{
Olga Kosheleva and Vladik Kreinovich
}

\begin{abstract}
We show that a natural formalization of the process of changing one's mind leads to such seemingly non-intuitive ideas as square root of "not" and complexvalued fuzzy degrees.
\end{abstract}

\section{Formulation of the Problem}

Everything is a matter of degree - at least our opinions. It is rare that we immediately become convinced in the truth of some statement. Ok, this happens in mathematics: once we hear (or read) and understand the proof, we are $100 \%$ convinced. However, outside mathematical proof, our degree of belief in a statement changes gradually. We may eventually reach the stage when we are absolutely convinced that a given statement is true (or when we are absolutely convinced that a given statement is false), but before we reach this stage, we go through intermediate stages, in which we only have a partial degree of belief in the given statement.

This idea of intermediate degrees of belief is one of the main ideas behind Zadeh's fuzzy logic (see, e.g., [2, 6, 10, 13, 15, 19]) - that everything is a matter of degree.

Simplest description of degrees - as numbers between 0 and 1. In the computers, "true" is represented by 1 and "false" by 0 . Thus, it is natural to represent intermediate degrees of belief by numbers intermediate between 0 and 1 - i.e., by numbers from the interval $[0,1]$. This is what Zadeh originally proposed, and this is what most fuzzy techniques still use.

What usually corresponds to full uncertainty. Full belief in a statement is described by the number 1 , full belief in its negation is described by the number 0 . So, a situation when we do not have any idea whether the statement is true or false

Olga Kosheleva and Vladik Kreinovich

University of Texas at El Paso, 500 W. University, El Paso, TX 79968, USA

e-mail: olgak@utep.edu,vladik@utep.edu 
is naturally represented by the value in the middle between 0 and $1-$ i.e., by the number 0.5 .

If we believe more in the given statement than in its negation, our degree of belief in this statement is larger than 0.5 - and the more we believe in this statement, the closer this degree is to 1 . If we believe less in the given statement than in its negation, our degree of belief in this statement is smaller than 0.5 - and the less we believe in this statement, the closer this degree is to 0 .

Sometimes we change our minds. For a mathematical theorem, once we have its proof, we know that this statement is true - and it will remain true. For other statements, the situation is different. We often change our minds, whether it is because we learn new facts, or because we analyze the existing facts more deeply.

Let us give an example.

Example of changing one's mind. A recent belletrized (= fictionalized) biography of Leonid Kantorovich, a Russian Nobel Prize winner in Economics [17], cites an interesting episode from the 1959 official visit of the Soviet leader Nikita Khruschev to the US. When in New York City, the Soviet delegation, accompanied by US interpreters and bodyguards, was walking along a street and saw a hamburger stand. The delegates asked the interpreter how much a hamburger costs. It looks like it was beneath the interpreter's dignity to eat cheap street food, so he did not know. He went and asked. At that time, it was 15 cents.

One of the Russian delegation members was surprised that it was so cheap, so he concluded that this item was heavily subsidized by the state.

To better understand the resulting exchange of opinions, it is important to mention that in the Soviet Union, everyone was required to study Marxism, and since one of the main theses of Marxism is that economy determines everything, studying economy was an absolute must. It turns out that in this group, Khruschev was the only one who took economy studies seriously. This is, by the way, how he was noticed and promoted and eventually became the leader - in his youth, he studied Marxism together with the wife of then Soviet leader Stalin. She noticed (and reported to her husband) that Khruschev was one of the few who was seriously studying instead of - like many other students - brown-nosing, denouncing, and playing other political games.

So, Khruschev replied that since this was a capitalist society, the owner of the hamburger stand does not get any subsidy from the state: moreover, the owner manages to be so efficient that he even gets some profit on these sales.

Based on this episode, it looks like Khruschev was right and his opponent was wrong, and this is the impression that one gets when reading this episode in the book (and this is probably the impression that the book's author had).

However, a deeper analysis of this situation makes one change his/her mind. Indeed, Khruschev was right about the owner of the hamburger stand, but in the big picture, he was largely wrong: food was very cheap in the US because agriculture was (and still largely is) heavily subsidized by the state (to be more precise, by the US federal government). 
What we do in this paper. In this paper, we analyze how such changing-of-mind can be naturally described in precise terms. We show that a natural formalization of this process leads to such seemingly exotic ideas as square root of "not" $[8,9,14,18]$ and complex-valued fuzzy logic $[1,3,4,5,7,11,16]$.

\section{Analysis of the Problem and the Resulting Derivation of Square Root of "Not" and of Complex-Valued Fuzzy Logic}

How can we describe changing-one's-mind in formal terms: analysis of the problem. In such changing-mind situations, we start with a degree of belief which is larger than $0.5-$ i.e., when we have an overall positive impression about the given statement, and we eventually shift to the overall negative impression -i.e., to a degree of belief which is smaller than 0.5 .

In many such situations, the resulting "negative" degree is about the same as the original "positive" degree of belief, i.e., we move from a degree which is larger than 0.5 by some amount to a new degree which is smaller than 0.5 by the same amount. In other words, we start with the degree $0.5+\varepsilon$, for some $\varepsilon>0$; then, we apply our analysis, and, by applying this analysis, we eventually reduce this degree to $0.5-\varepsilon$.

This is exactly negation. From the mathematical viewpoint, the transition from $0.5+\varepsilon$ to $0.5-\varepsilon$ is negation.

Indeed, in fuzzy logic, the degree of confidence in the negation "not $S$ " (denoted $\neg S$ ) of a given statement $S$ is usually interpreted as 1 minus the degree of confidence in the statement $S$ itself. So, if the original degree of belief in a statement $S$ was $0.5+\varepsilon$, then our degree of belief in $\neg S$ is equal to $1-(0.5+\varepsilon)=0.5-\varepsilon$.

How can we describe the intermediate stages of this transition? As we have mentioned earlier, all our transitions are gradual. In particular, when transitioning from the degree $0.5+\varepsilon$ to the degree $0.5-\varepsilon$, we pass half-way through an intermediate degree 0.5 .

How can we describe this half-way analysis-motivated transition, that leads us first from $0.5+\varepsilon$ to 0.5 and then from 0.5 to $0.5-\varepsilon$ ?

This is exactly what is usually called the square root of "not". We want an operation that, when repeated twice, would leads us from $0.5+\varepsilon$ to $0.5-\varepsilon$, i.e., whose composition with itself will lead to "not". In quantum logic, such operations are known as square roots of "not" - since repeating such operation twice leads to "not", just like multiplying twice by a square root of a number is equivalent to multiplying by the number itself.

A seemingly natural idea and why it does not work. At first glance, this is exactly how we want to describe this half-way transition: from $0.5+\varepsilon$ to 0.5 and then from 0.5 to $0.5-\varepsilon$. So, if we apply this transition to the situation when the original degree of belief in a statement $S$ was 0.5 , we will get the new degree $0.5-\varepsilon$. 
However, on second thought, this does not make much sense. Indeed, as we have mentioned earlier, in fuzzy logic, the degree 0.5 usually corresponds to the situations when we have no information about the statement at all. In such situations, no matter what analysis we apply, we do not get any new information, so we should stay at the same lack-of-information degree of belief 0.5.

Also, it is not clear where we should go from 0.5. For example, if we started with $0.6=0.5+0.1$, then after the first half-transformation, we should go to 0.5 , and then to $0.5-0.1=0.4$. On the other hand, if we started with $0.7=0.5+0.2$, then after the first half-transformation, we should go to 0.5 , and then to $0.5-0.2=0.3$. So where should we go from 0.5 - to 0.4 or to 0.3 ?

We need an additional parameter. The above argument shows that we cannot describe all intermediate stages of half-way changing-mind transition by the exact same number 0.5 , we need an additional parameter to distinguish between different situations, a parameter that enable us to differentiate between situations when we come from full uncertainty 0.5 , when we come from 0.6 , or when we come from 0.7 .

Towards the formal description of this situation. Without losing generality, let us describe the original value of the second parameter by 0 . Then, we start with a degree $(0.5+\varepsilon, 0)$, we go through an intermediate situation $(0.5, c)$ for some value $c$ (depending on $\varepsilon$ ) and then we get to the degree $(0.5-\varepsilon, 0)$.

The only case when the analysis does not change the situation is when we know nothing, i.e., when $\varepsilon=0$. In this case, the resulting state should be the same $(0.5,0)$, i.e., we should have $c=0$.

In other words, we need to describe a function $f$ that maps 2-D vectors into 2-D vectors and for which

$$
f(0.5+\varepsilon, 0)=(0.5, c(\varepsilon))
$$

and

$$
f(0.5, c(\varepsilon))=(0.5-\varepsilon, 0) .
$$

Let us linearize. We can expand the transformation $f$ in Taylor series. For small $\varepsilon$, we can keep only the linear terms in this expansion, and ignore quadratic and higher order terms. In general, a linear transformation $f\left(x_{1}, x_{2}\right)=\left(y_{1}, y_{2}\right)$, where $f_{1}\left(x_{2}, x_{2}\right)=y_{1}$ and $f_{2}\left(x_{1}, x_{2}\right)=y_{2}$, has the form

$$
\begin{aligned}
& f_{1}\left(x_{1}, x_{2}\right)=a_{1}+a_{11} \cdot x_{1}+a_{12} \cdot x_{2} \\
& f_{2}\left(x_{1}, x_{2}\right)=a_{2}+a_{21} \cdot x_{1}+a_{22} \cdot x_{2} .
\end{aligned}
$$

Let us analyze the situation. For the formula (1), expressions (3) and (4) take the form

$$
\begin{gathered}
0.5=a_{1}+a_{11} \cdot(0.5+\varepsilon) ; \\
c(\varepsilon)=a_{2}+a_{21} \cdot(0.5+\varepsilon) .
\end{gathered}
$$


The left-hand side of the formula (5) does not depend on $\varepsilon$, so the right-hand side should also be independent on $\varepsilon$, i.e., we should have $a_{11}=0$. Thus, we will have $a_{1}=0.5$, i.e., the formula (3) takes the form

$$
f_{1}\left(x_{1}, x_{2}\right)=0.5+a_{12} \cdot x_{2}
$$

We know that $c(0)=0$. Substituting $\varepsilon=0$ and $c(0)=0$ into the formula (6), we get $0=a_{2}+a_{21} \cdot 0.5$, hence $a_{2}=-0.5 \cdot a_{21}$. Thus, the formula (4) takes the form

$$
f_{2}\left(x_{1}, x_{2}\right)=a_{21} \cdot\left(x_{1}-0.5\right)+a_{22} \cdot x_{2},
$$

and the expression (6) takes the form $c(\varepsilon)=a_{21} \cdot \varepsilon$.

For the formula (2), the expressions (7) and (8) take the form

$$
\begin{aligned}
0.5-\varepsilon & =0.5+a_{12} \cdot a_{21} \cdot \varepsilon ; \\
0 & =a_{22} \cdot a_{21} \cdot \varepsilon .
\end{aligned}
$$

From (9), we conclude that $a_{12} \cdot a_{21}=-1$ and thus, $a_{21} \neq 0$. So, from (1), we conclude that $a_{22}=0$. Thus, the half-way transformation takes the form

$$
\begin{gathered}
f_{1}\left(x_{1}, x_{2}\right)=0.5+a_{12} \cdot x_{2} \\
f_{2}\left(x_{1}, x_{2}\right)=-\frac{1}{a_{12}} \cdot\left(x_{1}-0.5\right) .
\end{gathered}
$$

These formulas can be further simplified if we take into account that there is no fixed starting point for the auxiliary parameter. So, to make formulas simpler, instead of the original parameter $c$ (or, more generally, $x_{2}$ ), we can as well take a re-scaled parameter $c^{\prime} \stackrel{\text { def }}{=}-a_{12} \cdot c$ (correspondingly, $x_{2}^{\prime} \stackrel{\text { def }}{=}-a_{12} \cdot x_{2}$ ). In the new scale, the half-way transformation has the form

$$
\left(x_{1}, x_{2}^{\prime}\right) \rightarrow\left(0.5-x_{2}^{\prime}, x_{1}\right) .
$$

i.e., in terms of the difference $x_{1}^{\prime} \stackrel{\text { def }}{=} x_{1}-0.5$ that takes values from -0.5 to 0.5 , the form

$$
\left(x_{1}^{\prime}, x_{2}^{\prime}\right) \rightarrow\left(-x_{2}^{\prime}, x_{1}^{\prime}\right)
$$

This is exactly complex values! The transformation (14) is exactly what happens if we multiply a generic complex number $x_{1}^{\prime}+\mathrm{i} \cdot x_{2}^{\prime}$ by $\mathrm{i} \stackrel{\text { def }}{=} \sqrt{-1}$ :

$$
\left(x_{1}^{\prime}+\mathrm{i} \cdot x_{2}^{\prime}\right) \cdot \mathrm{i}=-x_{2}^{\prime}+\mathrm{i} \cdot x_{1}^{\prime} .
$$

Thus, we have indeed arrived at complex-valued fuzzy degrees. 
Olga Kosheleva and Vladik Kreinovich

\section{Acknowledgments}

This work was supported in part by the National Science Foundation grants 1623190 (A Model of Change for Preparing a New Generation for Professional Practice in Computer Science), and HRD-1834620 and HRD-2034030 (CAHSI Includes). It was also supported by the program of the development of the Scientific-Educational Mathematical Center of Volga Federal District No. 075-02-2020-1478.

The authors are greatly thankful to Scott Dick for his encouragement, and to the anonymous referees for their valuable suggestions.

\section{References}

1. S. Aghakhani and S. Dick, "An on-line learning algorithm for complex fuzzy logic", Proceedings of the 2010 International IEEE Conference on Fuzzy Sets and Systems FUZZ-IEEE'2010, pp. $1-7$.

2. R. Belohlavek, J. W. Dauben, and G. J. Klir, Fuzzy Logic and Mathematics: A Historical Perspective, Oxford University Press, New York, 2017.

3. Z. Chen, S. Aghakhani, J. Man, and S. Dick, "ANCFIS: A Neurofuzzy Architecture Employing Complex Fuzzy Sets", IEEE Transactions on Fuzzy Systems, 2011, Vol. 19, No. 2, pp. 305-322.

4. S. Dick, "Towards complex fuzzy logic", IEEE Transactions on Fuzzy Systems, 2005, Vol. 13, No. 3, pp. 405-414.

5. O. Kosheleva and V. Kreinovich, "Approximate nature of traditional fuzzy methodology naturally leads to complex-valued fuzzy degrees", Proceedings of the IEEE World Congress on Computational Intelligence WCCI'2014, Beijing, China, July 6-11, 2014.

6. G. Klir and B. Yuan, Fuzzy Sets and Fuzzy Logic, Prentice Hall, Upper Saddle River, New Jersey, 1995.

7. O. Kosheleva, V. Kreinovich, and T. Ngamsantivong, "Why complex-valued fuzzy? Why complex values in general? A computational explanation", Proceedings of the Joint World Congress of the International Fuzzy Systems Association and Annual Conference of the North American Fuzzy Information Processing Society IFSA/NAFIPS'2013, Edmonton, Canada, June 24-28, 2013, pp. 1233-1236.

8. V. Kreinovich, L. J. Kohout, and E. Kim, "Square root of 'not': a major difference between fuzzy and quantum logics", Proceedings of the 27th International Conference of the North American Fuzzy Information Processing Society NAFIPS'2008, New York, New York, May 19-22, 2008.

9. V. Kreinovich, L. J. Kohout, and E. Kim, "Square root of 'not': a major difference between fuzzy and quantum logics", International Journal of General Systems, 2011, Vol. 40, No. 1, pp. 111-127.

10. J. M. Mendel, Uncertain Rule-Based Fuzzy Systems: Introduction and New Directions, Springer, Cham, Switzerland, 2017.

11. H. T. Nguyen, V. Kreinovich, and V. Shekhter, "On the possibility of using complex values in fuzzy logic for representing inconsistencies", International Journal of Intelligent Systems, 1998, Vol. 13, No. 8, pp. 683-714.

12. H. T. Nguyen, C. L. Walker, and E. A. Walker, A First Course in Fuzzy Logic, Chapman and Hall/CRC, Boca Raton, Florida, 2019.

13. H. T. Nguyen, C. L. Walker, and E. A. Walker, A First Course in Fuzzy Logic, Chapman and Hall/CRC, Boca Raton, Florida, 2019.

14. M. A. Nielsen and I. L. Chuang, Quantum Computation and Quantum Information, Cambridge University Press, Cambridge, U.K., 2000. 
15. V. Novák, I. Perfilieva, and J. Močkoř, Mathematical Principles of Fuzzy Logic, Kluwer, Boston, Dordrecht, 1999.n

16. C. Servin, V. Kreinovich, and O. Kosheleva, "From 1-D to 2-D fuzzy: a proof that intervalvalued and complex-valued are the only distributive options", Proceedings of the Annual Conference of the North American Fuzzy Information Processing Society NAFIPS'2015 and 5th World Conference on Soft Computing, Redmond, Washington, August 17-19, 2015.

17. F. Spufford, Red Plenty, Faber and Faber, London, 2010.

18. M. J. Wierman, "The square root of not: geometric, permutation, and matrix representations", Proceedings of the 28th North American Fuzzy Information Processing Society Annual Conference NAFIPS'09, Cincinnati, Ohio, June 14-17, 2009.

19. L. A. Zadeh, "Fuzzy sets", Information and Control, 1965, Vol. 8, pp. 338-353. 